\title{
A Simple Method for Simulating Horizontal Ozone Concentration Fields over Coastal Areas: A Case Study of the Seoul Metropolitan Area, Korea
}

\author{
Cheol-Hee Kim*, Yoo-Keun Kim, Hwa Woon Lee, and Kyong-Hwan Seo \\ Division of Earth Environmental System, Pusan National University, Busan, 609-735, South Korea
}

Received 29 September 2007, accepted 18 February 2008

\begin{abstract}
This paper describes a simple semi-empirical photochemical simulation method to generate horizontal ozone $\left(\mathrm{O}_{3}\right)$ concentration fields over coastal areas. Based on a simple semi-empirical photochemical reaction model (SEGRS), consisting of a simple photochemical reaction set and a diagnostic wind model, aggregated VOC emission strength is empirically scaled from measured photochemical gas phase concentrations of $\left(\mathrm{O}_{3}-2 \mathrm{NO}-\mathrm{NO}_{2}\right)$ against cumulative actinic light flux for the case of relatively weak off-shore geostrophic wind at $850 \mathrm{hPa}$ in summer. This scaled emission rate for volatile organic compounds (VOCs) is equally applied to horizontal $\mathrm{O}_{3}$ concentration simulation under on-shore synoptic conditions, and results are compared with observations. The results indicate that spatial distribution patterns and temporal variations of spatially averaged ground level ozone concentrations are reasonably well simulated. In addition, from the more than 100 box-form SEGRS simulations, close agreement between simulated and observed daily maximum $\mathrm{O}_{3}$ concentrations suggests that the semi empirical SEGRS model has great potential in getting horizontal ozone distribution patterns. This indicates that this simple semi-empirical approach to the simulation of $\mathrm{O}_{3}$ concentration patterns using SEGRS makes for an easy alternative method in multi-year simulation for impact studies of $\mathrm{O}_{3}$ concentrations by lowering heavy computational cost.
\end{abstract}

Key words: Semi-empirical photochemical model, Ozone concentration simulation, Seoul metropolitan area, VOC emission strength Citation: Kim, C. H., Y. K. Kim, H. W. Lee, and K. H. Seo, 2009: A simple method for simulating horizontal ozone concentration fields over coastal areas: A case study of the Seoul metropolitan area, Korea. Terr. Atmos. Ocean. Sci., 20, 355-363, doi: 10.3319/TAO.2008.02.18.01(A)

\section{INTRODUCTION}

Ground-level ozone $\left(\mathrm{O}_{3}\right)$ adversely affects human health and vegetation, and duration of exposure and peak $\mathrm{O}_{3}$ concentrations have been recognized as important factors in impact assessment studies (Lefohn et al. 1988; Pedersen and Lefohn 1994; McDonnell et al. 1999). Toward precise long-term impact assessment studies of high $\mathrm{O}_{3}$ concentrations, multi-year photochemical model simulation has been recognized as the most promising method in assessing cumulative $\mathrm{O}_{3}$ exposure. Consequently, many deterministic complex chemistry transport models have been developed to provide the best consistency between the multi-year photochemical model's input and output fields (Sirois et al. 1999; Vautard et al. 2001), and the model has been evaluated over many big cities.

\footnotetext{
* Corresponding author

E-mail:chkim2@pusan.ac.kr
}

However, long-term simulation of the horizontal distribution of ozone concentrations with a detailed three dimensional photochemical model in a complex terrain area requires numerous accurate input data such as a variety of complicated wind fields and specific information on spatial and temporal variations of emissions of ozone precursors such as disaggregated volatile organic compounds (VOCs) and $\mathrm{NO}_{\mathrm{x}}$ $\left(\mathrm{NO}_{\mathrm{x}}=\mathrm{NO}+\mathrm{NO}_{2}\right)$. Among them, the dominant source of uncertainty for the simulation of photochemical oxidants including $\mathrm{O}_{3}$ is a lack of knowledge of disaggregated VOC emissions, consequently many methods have been suggested for assessing VOC emission strength (Goldan et al. 1995; Kleinman et al. 1998; Trainer et al. 2000). In most cases, it was found that the uncertainty could not be quantified in an objective manner. Furthermore fine-tuning of the sophisticated model parameters and their validation are long processes, requiring a lot of computer time. In addition, researches have stated that uncertainties in individual sources, 
such as VOCs, were mostly expressed as consisting of integration errors (Hannah et al. 1998; Kuhlwein and Friedrich 2000). Therefore, despite continuous advances in sophisticated chemistry-transport models for air quality, simulation of ozone concentrations in association with day-to-day weather events remains a very challenging problem.

Assessment of emission data for $\mathrm{O}_{3}$ precursors has been tried in many studies. Some studies employed very detailed three-dimensional photochemical reaction models to estimate and address uncertainty of emission inventory (Hannah et al. 1998; Vautard et al. 2003). Some researchers suggested validation processes for emissions of ozone precursors by comparing modeled results, obtained by scaling methods, against measurements (Pierson et al. 1990; Uno et al. 1997; Carmichael et al. 1998). In light of this, several methods such as elaborating on data assimilation methods for providing routine air pollution concentration have recently been attempted to provide three-dimensional ozone concentration fields (Elbern and Schmidt 2001; Vautard et al. 2001; Blond et al. 2003).

Recently, Kim et al. (2005) proposed a very simple photochemistry Eulerian transport model called the semiempirical photochemical reaction model (hereafter Semi Empirical GRS; SEGRS). This model is composed of a simple GRS photochemical reaction set combined with a diagnostic wind model for photochemical simulation and was tested over the Seoul metropolitan area in Korea. The simplicity of the SEGRS model is one of its most important features in that it can be used in very simple way to improve the sophisticated three-dimensional photochemical grid modeling, which is largely unfeasible given the uncertainties arising from space and time distributions of precise emission strengths. Kim et al. (2005) employed the SEGRS model to empirically scale aggregated VOC emission strength under appropriate meteorological conditions by comparing the simulated slope of $\left(\mathrm{O}_{3}-2 \mathrm{NO}-\mathrm{NO}_{2}\right)$ concentration as a function of cumulative actinic light flux against that of measurements on high surface ozone concentration days, and then modified the strength of the VOC emission rate. This scaling of VOC emission was performed under relatively weak offshore geostrophic winds at $850 \mathrm{hPa}$ in summer when the effect of horizontal advection was fairly small. This is due to a feature of the Seoul metropolitan area (Fig. 1) whereby the sea breeze (westerly flow) generated from the Yellow Sea moves against the synoptic easterly flow, making convergence within the western area of the target domain.

In this study, we introduce a simple semi-empirical method of scaling the aggregated total VOC emission rate using the SEGRS model by employing observed values of $\mathrm{O}_{3}, \mathrm{NO}_{\mathrm{x}}$ and sunlight fluxes. Next, we apply the scaled emission strength of VOCs conducted by Kim et al. (2005) to the on-shore synoptic condition to test the viability of this semi-empirical scaling method. Lastly, the results of an application of the box form of SEGRS to more than 100 summer cases is discussed in comparison with observations,

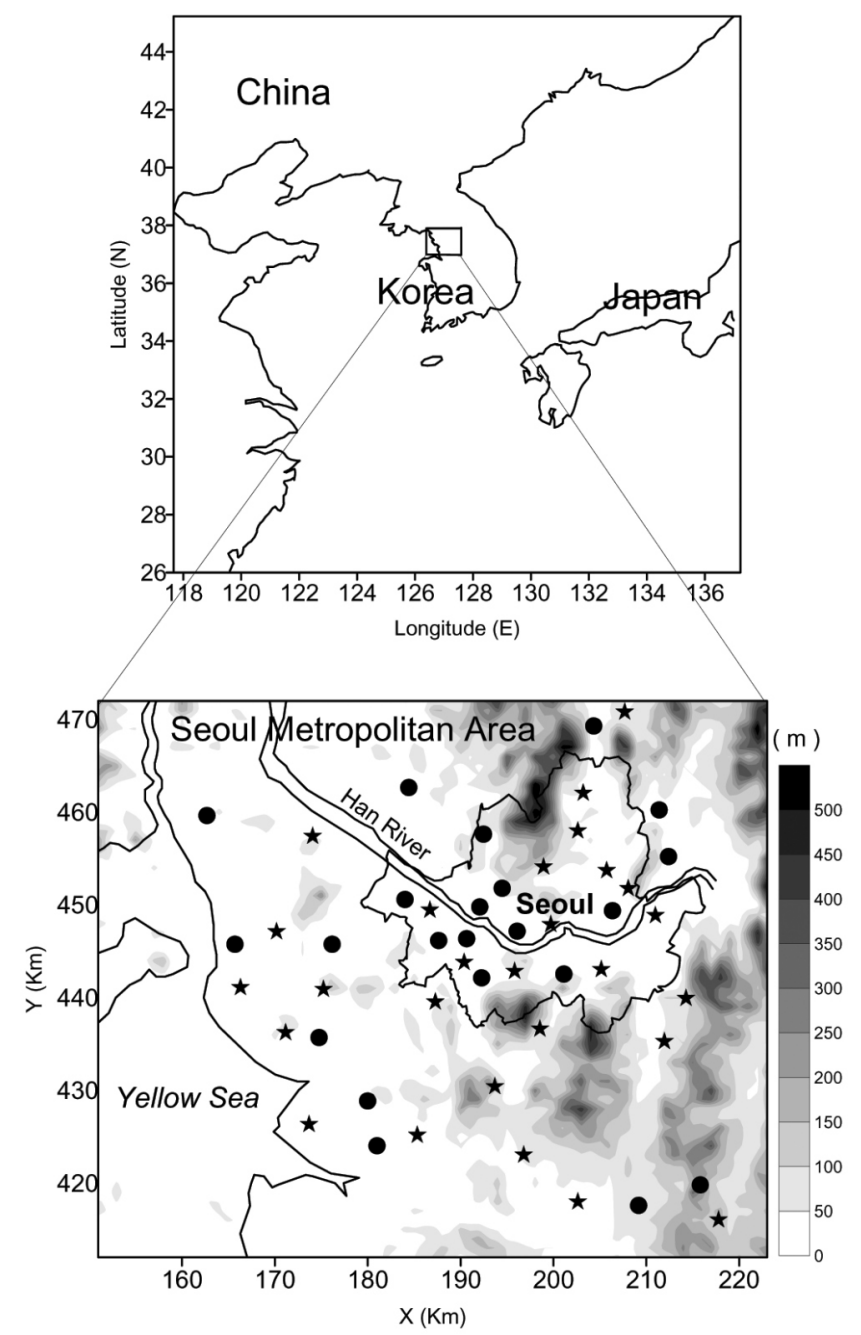

Fig. 1. The location of the study area, topography, locations of meteorological observation sites $(\bullet)$, and ozone monitoring sites $(\star)$ in the Seoul metropolitan area.

and the capability of the simple SEGRS model is evaluated here.

\section{PHOTOCHEMICAL AND METEOROLOGICAL MODEL DESCRIPTION}

A photochemical chemical module called GRS (Generic Reaction Set) developed by Azzi et al. (1992) is employed. It consists of the following reactions:

$$
\begin{aligned}
& \mathrm{ROC}+h v \stackrel{O_{2}}{\longrightarrow} \mathrm{RP}+\mathrm{ROC} \\
& \mathrm{RP}+\mathrm{NO} \longrightarrow \mathrm{NO}_{2} \\
& \mathrm{NO}_{2}+h v \stackrel{\mathrm{O}_{2}}{\longrightarrow} \mathrm{NO}+\mathrm{O}_{3} \\
& \mathrm{NO}+\mathrm{O}_{3} \longrightarrow \mathrm{NO}_{2} \\
& \mathrm{RP}+\mathrm{RP} \longrightarrow \mathrm{RP}
\end{aligned}
$$


$\mathrm{RP}+\mathrm{NO}_{2} \longrightarrow \mathrm{SGN}$

$\mathrm{RP}+\mathrm{NO}_{2} \longrightarrow \mathrm{SNGN}$

where ROC represents reactive organic compounds, RP the radical pool, SGN the stable gaseous nitrogen products, and SNGN the stable non-gaseous nitrogen products.

Equation (1) represents all processes that lead to radical production from VOCs through photo-oxidation. Therefore, regenerated ROC has to be considered as a surrogate for all products of the oxidation of emitted VOCs. The rate constant $k_{l}$ for ROC in Eq. (1) is expressed as a function of the $\mathrm{NO}_{2}$ photolysis rate constant, the weighted mean activity coefficient of the ROC, and the temperature such that: $k_{1}=$ $\bar{a}_{\text {ROC }} \cdot k_{3} \cdot f(\mathrm{~T})$, where $k_{3}$ is the photolysis rate constant of $\mathrm{NO}_{2}$ in Eq. (3) and $f(\mathrm{~T})=\exp [-4700(1 / \mathrm{T}-1 / 316)]$, where $\mathrm{T}$ is the temperature (Azzi and Johnson 1991).

The weighted activity coefficient $\bar{a}_{R O C}$ is determined for the mixture of ROC components from $\bar{a}_{R O C}=\frac{\sum_{i=1}^{n} a_{i} \cdot C_{i}}{\sum_{i=1}^{n} C_{i}}$, where $n$ is the number of ROC components in the mixture, $C_{i}$ the concentration of component $i$, and $a_{i}$ the reactivity coefficient for component $i$. To determine the aggregated ROC activity coefficient, we have to know the individual concentrations and reactivities of VOCs, the weighted averaged reactivity $\left(E_{R O C}=\sum_{i=1}^{n} E_{i} \cdot a_{i}\right)$ with the emission rate of VOCs $\left(E_{i}\right)$, and the reactivity scaling factor $\left(a_{\mathrm{i}}\right)$. In this simple method, aggregated reactivity, $\bar{a}_{R O C}$, was empirically scaled due to a lack of detail pertaining to the emission rate and scaling factor of each of the disaggregated VOC components (Kim et al. 2005).

A three dimensional diagnostic wind generation model is used to construct diurnal varying wind and turbulence fields using hourly averaged surface observation data obtained from the meteorological sites indicated in Fig. 1. The objective analysis methodology used in this study is a fast, objective, three-dimensional wind analyses in complex terrain by incorporating two important physical constraints of mass conservation and limitation of atmospheric stability on vertical displacement (Park and Kim 1999). A grid structure of $3 \times 3 \mathrm{~km}$ horizontal spacing with 15 vertical levels is used in the terrain following vertical coordinate, and horizontal advection is solved using the Galerkin technique with chapeau functions as finite elements (Toon et al. 1988; Park and Kim 1999; Kim et al. 2005).

\section{A SIMPLE METHOD OF ASSESSING AGGREGATED VOC EMISSION}

Given sufficient contrast between land and sea temperature, the formation of a sea-breeze depends on the balance between converging winds, which act to form a sea breeze front, and vertical mixing over land, caused by thermal convection, which acts to prevent its forming (Simpson 1994). It is, however, possible for a sea breeze front to form on a day of light onshore wind, provided that the land and sea temperature difference is large enough. On such days, the convergence of the winds will be small and a sea breeze front might not form until late in the day.

In calm weather or with only a light opposing (offshore) wind, a sea breeze is able to extend its influence gradually on the transport of urban air pollutants moving them to outer regions of urban areas. However, when the off-shore wind is strong enough, a sea-breeze can develop over the coastal area and start to form a convergence zone near the coast. While the sea breeze itself continues to blow behind the front and air ascends along the line where the converging winds meet, high mesoscale convergence may be moving slowly inland or remaining stationary. This is implying that emitted ozone precursors all take part in the photochemical reaction within the target domain, and thus there is little possibility of transport outside of the boundary, making for high ozone levels within the target domain.

In the Seoul metropolitan area, the case of offshore synoptic condition is scarcely observed. Kim et al. (2005) chose offshore geostrophic wind (easterly) at the $850 \mathrm{hPa}$ to scale the emission inventory of VOCs over Seoul's metropolitan area. In order to determine the scaling factor of VOC emission strength for the given opposing wind, the relation between observations of $\left(\mathrm{O}_{3}-2 \mathrm{NO}-\mathrm{NO}_{2}\right)$ versus light flux was derived by invoking the steady state of $\mathrm{RP}[d(R P) / d t \approx 0]$ and small concentrations of RP $\left[(\mathrm{RP})^{2} \approx 0\right]$ in Eq. (2) above (Venkatram et al. 1994). This yields the relation: $k_{l}(R O C)=$ $d\left(\mathrm{O}_{3}-2 \mathrm{NO}-\mathrm{NO}_{2}\right) / d \int f(T) k_{3} d t$, implying that the slope of $\left(\mathrm{O}_{3}-2 \mathrm{NO}-\mathrm{NO}_{2}\right)$ concentration versus the cumulative actinic flux $\left[\int f(T) k_{3}\right]$ obtained from monitoring and meteorological observation sites, provides the empirical approach for assessing total VOC emission. In Seoul metropolitan area a weak easterly (off-shore) geostrophic wind interacts with a westerly developed sea breeze starting from the Yellow Sea during the daytime, and as a result maximum $\mathrm{O}_{3}$ concentration occurs in the western part of Seoul.

Under the above meteorological conditions, SEGRS model in a box form was run several times by doubling the strength of VOC emissions. The simulated $\left(\mathrm{O}_{3}-2 \mathrm{NO}-\mathrm{NO}_{2}\right)$ concentrations vs. cumulative actinic fluxes performed by the simple model, and the optimal slopes $\left[=d\left(\mathrm{O}_{3}-2 \mathrm{NO}-\mathrm{NO}_{2}\right) /\right.$ $\left.d \int f(T) k_{3} d t\right]$ of the curves are fitted against observations repeatedly in order to get a reasonable emission strength of aggregated VOC (Fig. 2). The differences in slopes of both simulated and measured curves reveal quantitatively whether VOC emission strength is underestimated or not. Figure 2 shows that the emission strength of VOC should be increased approximately by a factor of 4 , indicating the original emission strength of VOC was underestimated by the same factor. Therefore we increased VOC emission rates by the same factor 


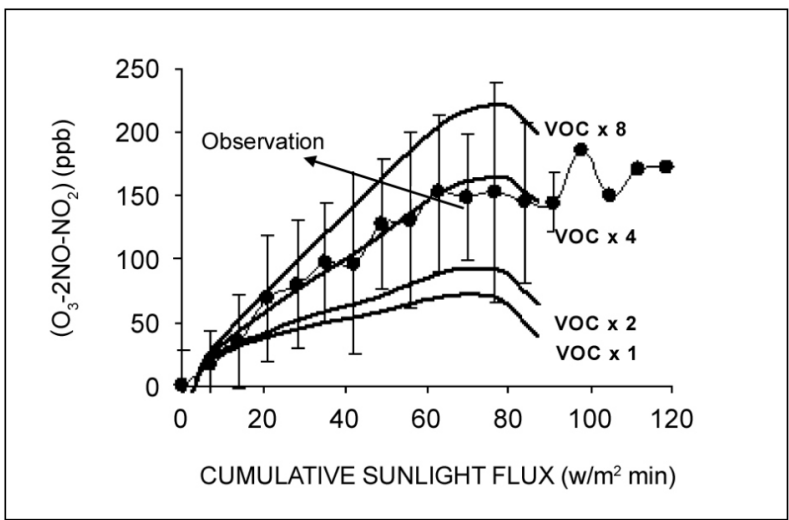

Fig. 2. Variations of observed and simulated $\left(\mathrm{O}_{3}-\mathrm{NO}_{2}-2 \mathrm{NO}\right)$ concentrations with cumulative actinic flux in Seoul metropolitan area. The simulated curves are obtained with the original VOC emission and increased emission by a factor of 2,4 , and 8 , respectively. The filled circles represent observations with plus and minus one standard deviation.

in each of the grid points over the target domain. Figure 3 shows the horizontal distributions of emission strength of both $\mathrm{NO}_{\mathrm{x}}$, and empirically scaled total VOC (i.e., VOC increased by a factor of 4). More details are found in Kim et al. (2005).

\section{CASE SELECTION, INITIAL AND BOUNDARY CONDITIONS}

In order to evaluate the feasibility of scaled VOC emission, onshore (westerly) synoptic cases in summer provide the selected fields for the study to simulate horizontal $\mathrm{O}_{3}$ concentration. High pollution potential days in summer with relatively weak westerly geostrophic wind (i.e., less $<5 \mathrm{~m} \cdot \mathrm{s}^{-1}$ ) at $850 \mathrm{hPa}$ are chosen. High pollution potential days have

(a)

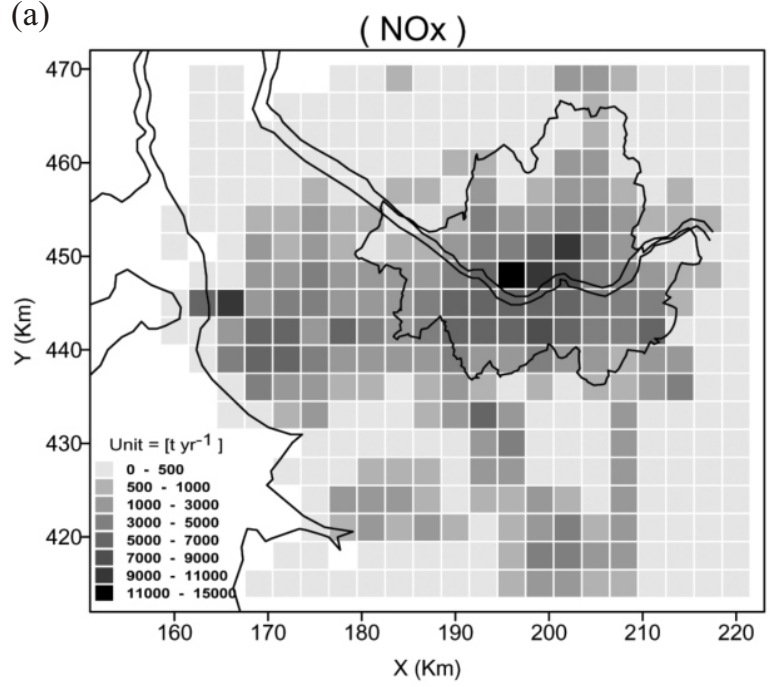

been identified by the complex potential index (Jung et al. 1996). The chosen synoptic cases for this study consist of 10 days in total in summer (14 June, 12 August in 1991; 1 June in 1992; 3, 5 July in 1993; 21 August in 1998; 26 June in 1999; 26 July in 2000; 5 June, 5 July in 2003). The common synoptic feature of the chosen cases is a broad area of high pressure at $850 \mathrm{hPa}$ off the south coast of the Korean Peninsula with higher insolation, weak wind speed, and moderate relative humidity.

The initial conditions used are the same as for the previous study, and $\mathrm{O}_{3}$ and $\mathrm{ROC}$ concentrations remain at zero at the boundaries. The entire model simulation is performed over $48 \mathrm{~h}$ commencing at $0100 \mathrm{LST}$ with a diurnally varying diagnosed meteorological field. The first day is used as spin-up time for all species, and the results of $24 \mathrm{~h}$ simulation are used as initial conditions for the next $24 \mathrm{~h}$ simulation of ground-level $\mathrm{O}_{3}$ concentration. In addition, we simulated maximum $\mathrm{O}_{3}$ concentration for 116 days in summer using a box form of the SEGRS in order to discuss the capability of SEGRS for the various synoptic cases. The simulated maximum $\mathrm{O}_{3}$ concentrations are compared with observations, and the model's capabilities are statistically discussed.

\section{RESULTS}

\subsection{Wind Fields}

Figure 4 shows simulated wind vectors at $10 \mathrm{~m}$ above the ground at 1200,1800, and 2400 LST for the selected high pollution potential days for the case of weak on-shore geostrophic wind $\left(2.9 \mathrm{~m} \cdot \mathrm{s}^{-1}\right.$ from $278.2^{\circ}$ direction) at $850 \mathrm{hPa}$. Southwesterly flows prevail over the land area while westerly flows prevail over both the entire coast and Yellow Sea

(b)

\section{( THC )}

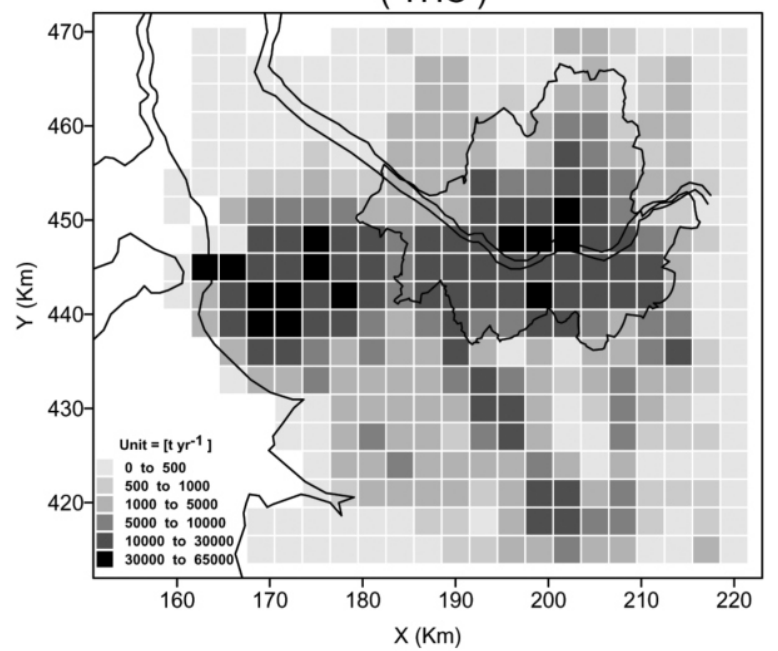

Fig. 3. Spatial distributions of: (a) $\mathrm{NO}_{\mathrm{x}}$ emission $\left(\mathrm{t} \cdot \mathrm{km}^{-2} \mathrm{yr}^{-1}\right)$; and (b) scaled annual total amount of VOC emission $\left(\mathrm{t} \cdot \mathrm{km}^{-2} \mathrm{yr}^{-1}\right)$ in the $\mathrm{Seoul}$ metropolitan area. 

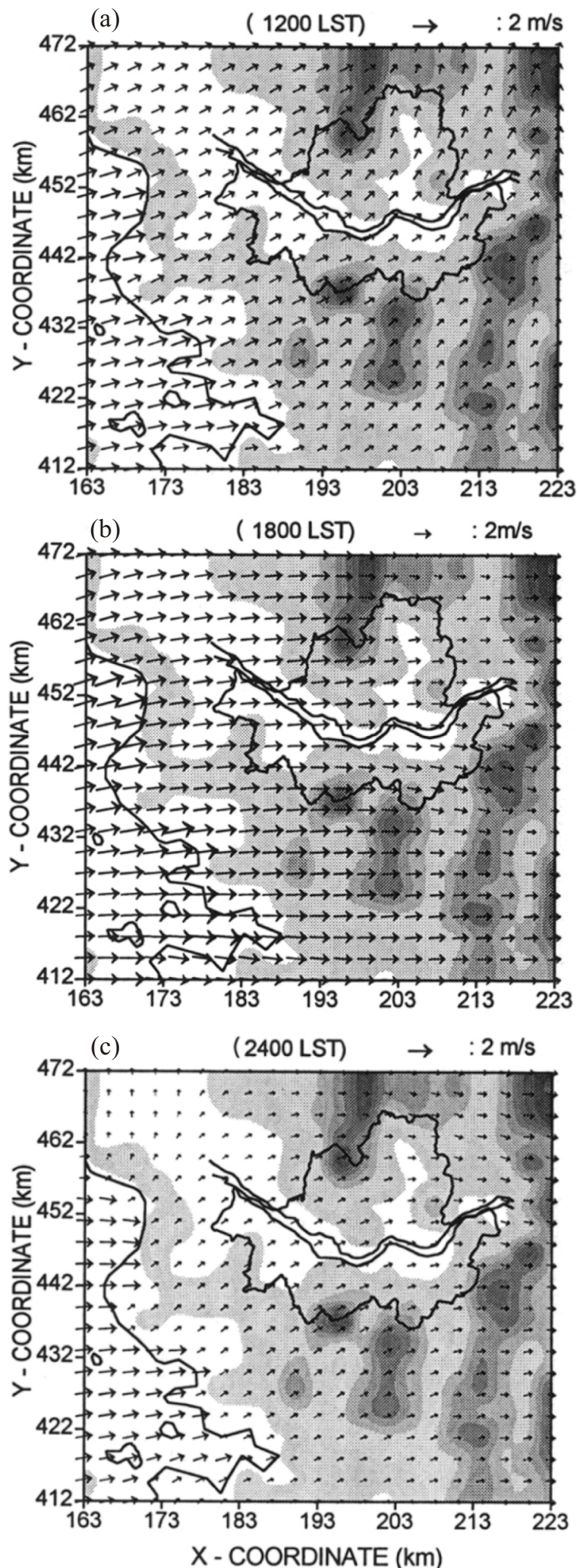

Fig. 4. The simulated wind vectors at $10 \mathrm{~m}$ above the ground at 1200 , 1800 , and 2400 LST for the selected 10 days.

at 1200 LST. This is associated with a developing sea breeze. At 1200 LST the westerly flows over the west coast keep moving inland, and the westerly winds along the west- ern coastline are intensified due to the influence of the intensified sea breeze front moving from the Yellow Sea, and penetrate inland until 18 LST (Fig. 4). At 2400 LST the sea breezes are sharply weakened while very weak down valley winds begin to develop over the mountain area.

\subsection{Photochemical $\mathrm{O}_{3}$ Concentrations and Discussion}

Figure 5 shows the spatial distributions of the simulated and observed $\mathrm{O}_{3}$ concentrations. The model simulation indicates that precursors emitted in Seoul and coastal areas are transported eastward by westerlies during the day. At 1100 LST, precursors are transported eastward more rapidly from the coastal area due to an intensified westerly moving sea breeze front (Fig. 5b). Although the simulated maximum $\mathrm{O}_{3}$ concentration $(98 \mathrm{ppb})$ is slightly lower than that of the observations (110 ppb) in the analysis domain, these simulated horizontal ozone concentration distribution patterns are similar to observed features in Figs. 5e and f. However, in comparison with measurements, relatively lower simulated $\mathrm{O}_{3}$ concentrations are found in the western part of the coastal region where high $\mathrm{NO}_{2}$ and $\mathrm{VOC}$ emission sources are located along the western coastlines as indicated in Fig. 3, while relatively higher observed concentrations are found over the eastern part of Seoul. This is presumably due to the rapid transportation of ozone precursors by the strong westerly sea breeze coupled with synoptic westerlies. In the afternoon, higher $\mathrm{O}_{3}$ concentrations are found over the eastern part of Seoul, also showing some outflow of high $\mathrm{O}_{3}$ concentrations across the eastern boundary. Although the figure is not shown here, the modeled diurnal trends of spatially averaged ozone concentrations are in reasonably good agreement with the observations. There is no significant bias except in the coastal area where relatively lower concentrations are simulated. This discrepancy might be associated with the assumed no flux western boundary condition in the lateral. It is evident from these results that the present simple SEGRS model can be used effectively as a three dimensional Eulerian photochemical model provided more realistic boundary conditions are assumed.

Statistical comparisons between the simulated and the observed $\mathrm{O}_{3}$ concentrations are performed using the method discussed by Fox (1981). The objectively analyzed hourly observed $\mathrm{O}_{3}$ concentrations and the simulated $\mathrm{O}_{3}$ concentrations in the $3 \times 3 \mathrm{~km}$ gridded domain are used for statistical analysis. The paired comparisons for hourly $\mathrm{O}_{3}$ concentrations indicate low Root Mean Square Error (RMSE) of $16.2 \mathrm{ppb}$, and high correlation coefficients more than 0.84 , suggesting that SEGRS has great potential to be used as a practical photochemical reaction model for the simulation of horizontal $\mathrm{O}_{3}$ concentration fields in the Seoul metropolitan area.

In evaluating an air pollution model, another important criterion is its ability to simulate maximum concentrations. 

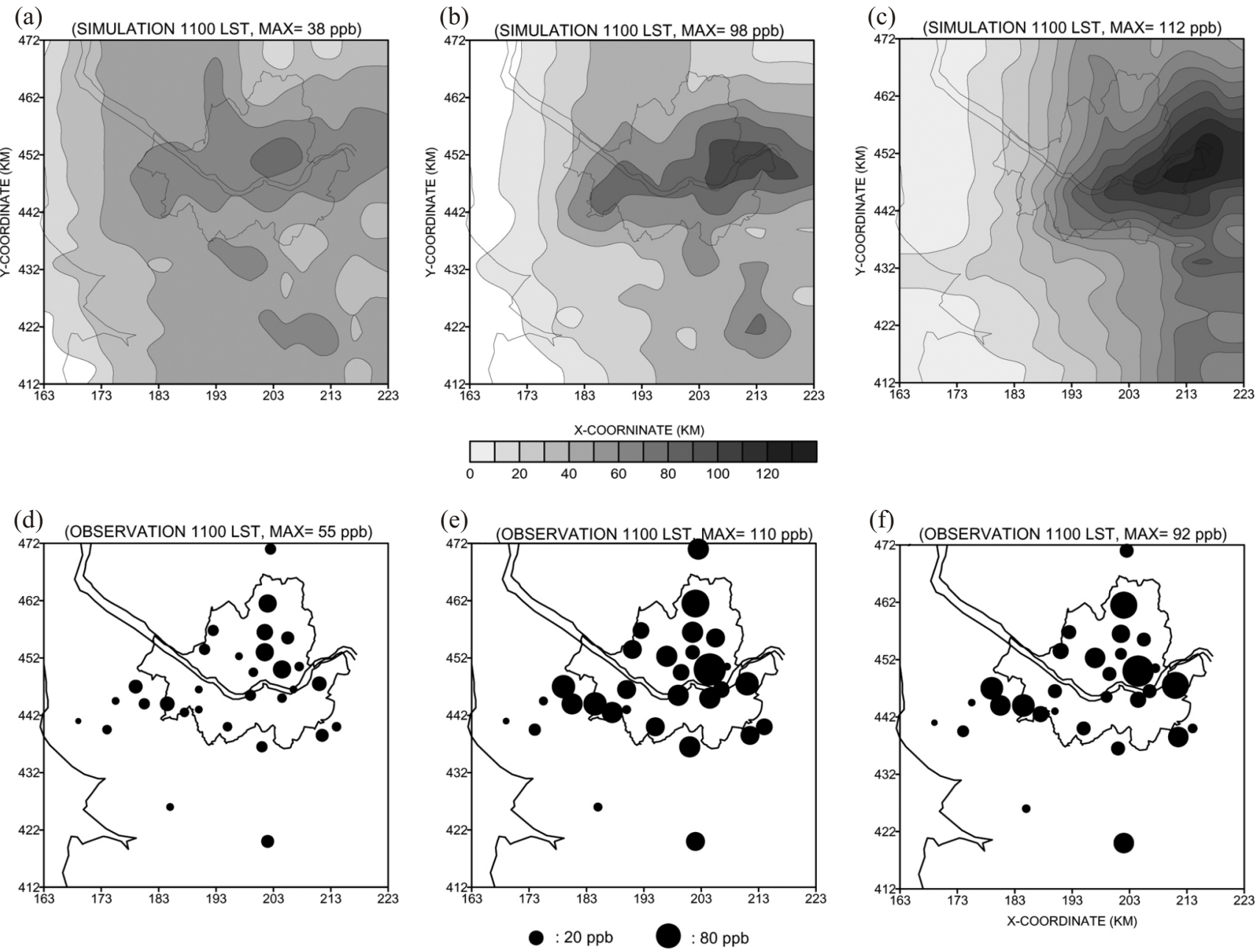

Fig. 5. Spatial distributions of simulated (left panel) and observed (right panel) ozone concentrations at 1100, 1400, and 1700 LST for the selected 10 days.

We first selected multi-cases of clear days (cloud cover $\leq 5 / 10$ ) in summer with geostrophic wind speed of less than $5 \mathrm{~m}$. $\mathrm{s}^{-1}$ at $850 \mathrm{hPa}$, regardless of synoptic wind direction. The selected days contain a total of 116 cases for the period from 1998 to 2003 in the Seoul metropolitan area. The averaged cloud cover and geostrophic wind speed at $850 \mathrm{hPa}$ was found to be $(2.9 / 10)$ and $3.1 \mathrm{~m} \cdot \mathrm{s}^{-1}$ for the chosen cases, respectively. Next, diurnal variation of $\mathrm{O}_{3}$ concentration for every selected case is simulated based on the box form of SEGRS. Finally, we performed statistical analysis of the paired maximum $\mathrm{O}_{3}$ concentrations between observed and simulated values. Although statistical comparison of observed and simulated concentrations may not reveal the causes of discrepancies, it can tell much about the nature of the mismatch.

Figure 6 shows a scatterplot comparing the maximum $\mathrm{O}_{3}$ concentrations between observations and simulations. As can be seen in the Fig. 6, the correlation and mean of residuals between the observed and simulated $\mathrm{O}_{3}$ concentrations are found to be 0.7 and $12.4 \mathrm{ppb}$, respectively. This not

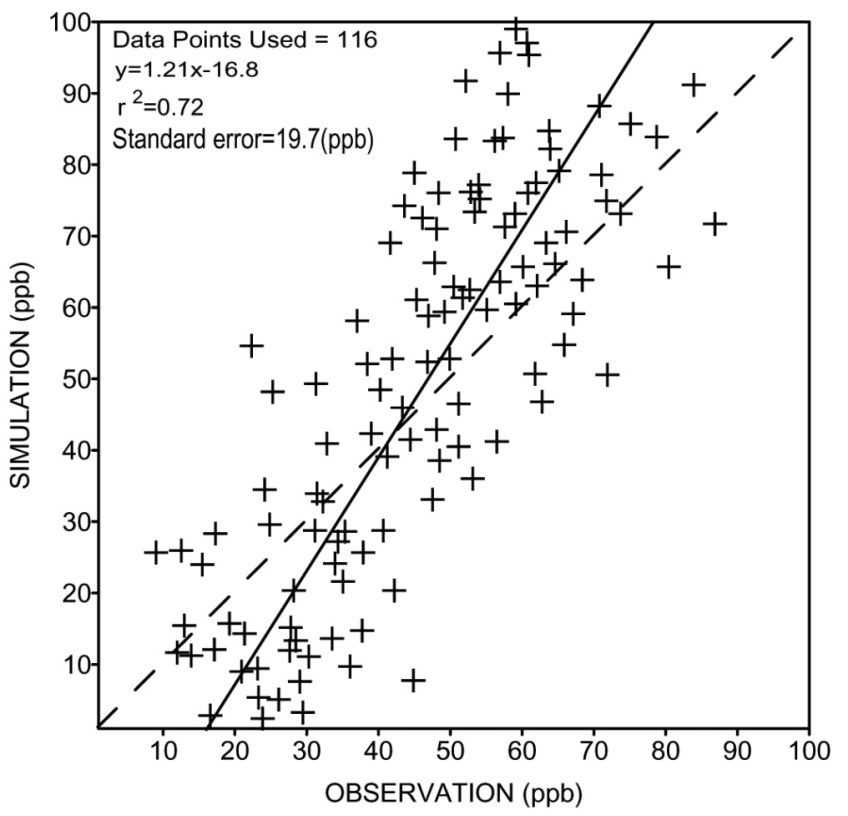

Fig. 6. Comparison between observed and simulated maximum $\mathrm{O}_{3}$ concentrations for the various synoptic cases. 
only implies that the SEGRS model is measuring an acceptable degree to which the magnitude of the simulations increases linearly with the magnitude of the observations, but also showing that the model does not predominantly overpredict observed concentrations. However, on both higher and lower concentration days, the level of agreement is found to be generally not as good. For example, the model tends to underestimate $\mathrm{O}_{3}$ concentrations on days of low $\mathrm{O}_{3}$ concentrations, and vice versa (Fig. 6). In addition, simulated timing of occurrence of maximum $\mathrm{O}_{3}$ concentrations shows on average $1 \sim 2 \mathrm{hr}$ time delay (not shown). This is because the phasing of simulated $\mathrm{O}_{3}$ concentrations depends on all the physical and photochemical processes involved. Nevertheless the close agreement between observed and simulated behavior suggests that the present SEGRS model overall portrays maximum levels of $\mathrm{O}_{3}$ concentrations. Aside from the agreement, however, it should be argued that the inclusion of a boundary condition and its effects on $\mathrm{O}_{3}$ concentrations in the western coastal area may improve the results.

Figure 7 shows the frequency distribution of the residuals, i.e., simulated minus observed maximum $\mathrm{O}_{3}$ concentrations. Approximately $77 \%$ of the maximum $\mathrm{O}_{3}$ concentrations are within $\pm 17.5 \mathrm{ppb}$ of each other. However, the distribution in Fig. 7 is skewed to the right with the skewness of +1.95 , indicating that the model tends to overestimate high $\mathrm{O}_{3}$ concentrations as illustrated in Fig. 6. Overall the distribution of residual tendency is seen as a function of observed $\mathrm{O}_{3}$ concentrations as illustrated in both Figs. 6 and 7. This might be associated with existing inherent limitations of the simplified photochemical reaction set [i.e., VOCs is all fixed through the photochemical process as indicated in Eq. (1)]. Aside from this tendency of SEGRS, the simulated spatial and maximum $\mathrm{O}_{3}$ concentrations agree closely with observations without significant bias.

This study suggests that the simple semi-empirical reaction model, SEGRS, can be used effectively to provide horizontal patterns of ozone concentrations in a very simple and cheap way. This is based on the fact that the complicated physical-chemical model generally requires numerous accurate input data such as disaggregated sources of VOC emissions, wind fields, and initial fields for various chemical components. In particular, uncertainty is difficult to treat quantitatively in most physical-chemical models. In light of this, the SEGRS model presented in this study offers an alternative way of producing horizontal $\mathrm{O}_{3}$ concentration fields for conducting multi-year simulation or long-term $\mathrm{O}_{3}$ impact assessment that does not require heavy computational cost.

\section{SUMMARY AND CONCLUSION}

In this study, a simple semi-empirical photochemical simulation model and its capability to simulate horizontal ozone concentration patterns over the Seoul metropolitan area was described. A simple semi-empirical reaction (SEGRS) model consisting of diagnostic wind field and simple GRS photochemical reactions was employed. Based on this model aggregate VOC emission strength is empirically scaled from measured photochemical gas phase concentrations of $\left(\mathrm{O}_{3}-2 \mathrm{NO}-\mathrm{NO}_{2}\right)$ against cumulative actinic light flux for the case of relatively weak off-shore geostrophic wind at $850 \mathrm{hPa}$ in summer. Also some case studies are analyzed to evaluate the capability of SEGRS for simulating horizontal patterns and maximum levels of $\mathrm{O}_{3}$ concentrations over the Seoul metropolitan area.

The results showed that using aggregated VOC emission strength scaled by SEGRS, the semi empirical model simulates well ground-level $\mathrm{O}_{3}$ concentrations for the case of offshore geostrophic wind (westerly) at $850 \mathrm{hPa}$, except in the western coastal region where ozone concentration was underestimated presumably due to boundary influx from the outer domain. Application of the box form of SEGRS to the various synoptic cases shows overall a reasonable level of maximum $\mathrm{O}_{3}$ concentration simulations in comparison with observations with a correlation coefficient of more than

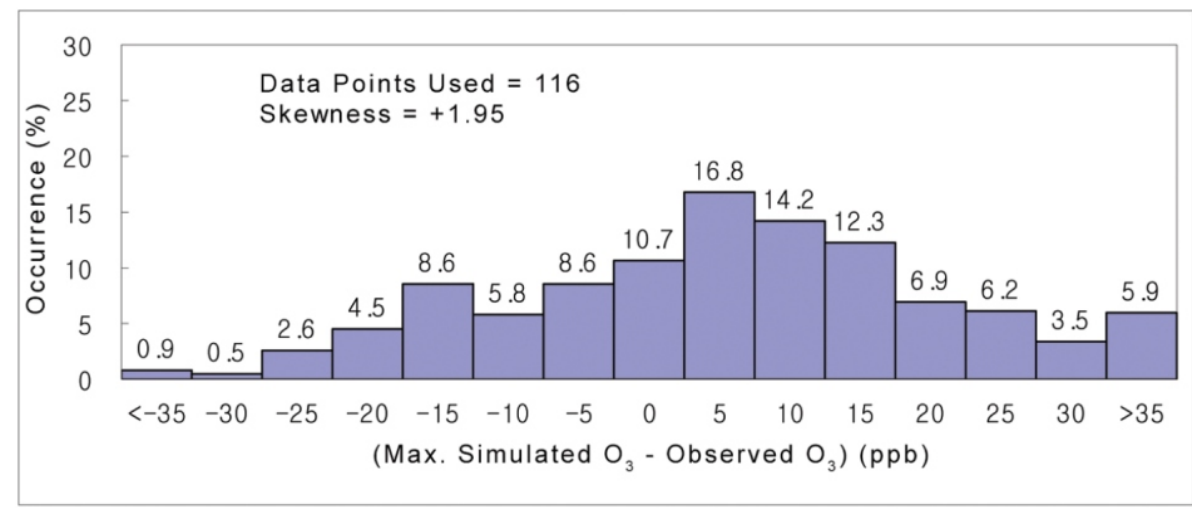

Fig. 7. Frequency distribution of residuals between simulated and observed maximum $\mathrm{O}_{3}$ concentrations for the various synoptic cases. 
0.7 , despite the model having a tendency to over predict higher observations. These results described above together with other tests indicate that the SEGRS model is able to reproduce the important horizontal features of $\mathrm{O}_{3}$ concentrations over the Seoul metropolitan area. It was thus found that the semi-empirical ozone simulation model based on GRS chemical reactions could be effectively used to generate ozone concentration patterns given an appropriate emission rate of ozone precursors over the coastal area. It is also going to be argued that a more realistic western boundary condition may improve the simulation results. Therefore further sensitivity testing including boundary flux over the Seoul metropolitan area is going to be tested to get more precise horizontal ozone distributions using the semi-empirical photochemical SEGRS model. In addition, SEGRS is going to be applied to simulate $\mathrm{O}_{3}$ concentrations in other urban areas to get more trustworthy performance and model validation.

Acknowledgements This work was funded by the Korea Meteorological Administration Research and Development Program under Grant CATER 2009-3212.

\section{REFERENCES}

Azzi, M. and G. M. Johnson, 1991: Notes on the generic reaction set model (GRS V 1.1). CSIRO Document, CSIRO Division of Coal and Energy Technology, New South Wales, Australia, December 1991.

Azzi, M., G. M. Johnson, and M. Cope, 1992: An introduction to the genetic reaction set photochemical smog mechanism. In Proc. $11^{\text {th }}$ Int. Clean Air Conf. $4^{\text {th }}$ Regional IUAPPA Conf., Brisbane, Australia, July 1992.

Blond. N, L. Bel, and R. Vautard, 2003: Three-dimensional ozone data analysis with an air quality model over the Paris area. J. Geophys. Res., 108, 4744, doi: 10.1029/2003JD 003679. [Link]

Carmichael, G. R., I. Uno, M. Phadnis, Y. Ahang, and Y. Sunwoo, 1998: Tropospheric ozone production and transport in the springtime in East Asia. J. Geophys. Res., 103, 10649-10671, doi: 10.1029/97JD03740. [Link]

Elbern, H. and H. Schmidt, 2001: Ozone episode analysis by four-dimensional variational chemistry data assimilation. J. Geophys. Res., 106, 3569-3590, doi: 10.1029/2000JD 900448. [Link]

Fox, D. G., 1981 : Judging air quality model performance. Bull. Amer. Meteor. Soc., 62, 599-609, doi: 10.1175/1520-0477 (1981)062<0599:JAQMP>2.0.CO;2. [Link]

Goldan, P. D., M. Trainer, W. C. Kuster, D. D. Parrish, J. Carpenter, J. M. Roberts, J. E. Yee, and F. C. Fehsenfeld, 1995: Measurements of hydrocarbons, oxygenated hydrocarbons, carbon monoxide, and nitrogen oxides in an urban basin in Colorado: Implications for emission inventories. J. Geophys. Res., 100, 22771-22783, doi: 10.1029/95JD01369. [Link]
Hannah, S. R., J. C. Chang, and M. E. Fernau, 1998: Monte Carlo estimates of uncertainties in predictions by a photochemical grid model (UAM-IV) due to uncertainties in input variables. Atmos. Environ., 32, 3619-3628, doi: 10.1016/S1352-2310(97)00419-6. [Link]

Jung, Y. S., S. U. Park, and I. H. Yoon, 1996: Characteristic features of local air quality associated with meteorological conditions. J. Korean Meteor. Soc., 32, 271-290. (in Korean)

Kim, C. H., S. U. Park, and C. K. Song, 2005: A simple semiempirical photochemical model for the simulation of ozone concentration in the Seoul metropolitan area in Korea. Atmos. Environ., 39, 5597-5607, doi: 10.1016/j.atmosenv. 2005.06.016. [Link]

Kleinman, L. I., P. H. Daum, D. G. Imre, C. Cardelino, K. J. Olszyna, and R. G. Zika, 1998: Trace gas concentrations and emissions in downtown Nashville during the 1995 Southern Oxidants Study/Nashville intensive. J. Geophys. Res., 103, 22545-22553, doi: 10.1029/98JD00622. [Link]

Kuhlwein, J. and R. Friedrich, 2000: Uncertainties of modeling emissions from road transport. Atmos. Environ., 34, 46034610, doi: 10.1016/S1352-2310(00)00302-2. [Link]

Lefohn, A. S., J. A. Laurence, and R. J. Kohut, 1988: A comparison of indices that describe the relationship between exposure to ozone and reduction in the yield of agricultural crops. Atmos. Environ., 22, 1229-1240, doi: 10.1016/ 0004-6981(88)90353-8. [Link]

McDonnell, W. F., D. E. Abbey, N. Nishino, and M. D. Lebowitz, 1999: Long-term ambient ozone concentration and the incidence of asthma in nonsmoking adults: The smog study. Environ. Res., 80, 110-121, doi: 10.1006/enrs.1998.3894. [Link]

Park, S. U. and C. H. Kim, 1999: A numerical model for the simulation of $\mathrm{SO}_{2}$ concentrations in the Kyongin region Korea. Atmos. Environ., 33, 3119-3132, doi: 10.1016/ S1352-2310(98)00335-5. [Link]

Pedersen, U. and A. S. Lefohn, 1994: Characterizing surface ozone concentrations in Norway. Atmos. Environ., 28, 89101, doi: 10.1016/1352-2310(94)90025-6. [Link]

Pierson, W. R., A. W. Gertler, and R. L. Bradow, 1990: Comparison of the SCAQS tunnel study with other on road vehicle emission data. J. Air Waste Manag. Assoc., 40, 1495-1504.

Simpson, J. E., 1994: Sea breeze and local winds, Cambridge University Press, 234 pp.

Sirois, A., J. A. Pudyklewicz, and A. Kallaur, 1999: A comparison between simulated and observed ozone mixing ratios in Eastern North America. J. Geophys. Res., 104, $21397-$ 21423, doi: 10.1029/1999JD900423. [Link]

Toon, O. B., R. P. Turco, D. Westphal, R. Malone, and M. S. Liu, 1988: A multidimensional model for aerosols: Description of computational analogs. J. Atmos. Sci., 45, 21232144, doi: 10.1175/1520-0469(1988)045<2123:AMMFAD> 2.0.CO;2. [Link]

Trainer, M., D. D. Parrish, P. D. Goldan, J. Roberts, and F. C. Fehsenfeld, 2000: Review of observation-based analysis 
of the regional factors influencing ozone concentrations. Atmos. Environ., 34, 2045-2061, doi: 10.1016/S13522310(99)00459-8. [Link]

Uno, I., S. Wakamatsu, H. Ueda, K. Murano, S. Sakamaki, H. Kurita, H. Satsumabayshi, and S. Horai, 1997: Behavior of secondary pollutants and volcanic $\mathrm{SO}_{2}$ over Kyushu during a spring high pressure system. J. Jpn. Soc. Atmos. Environ., 32, 404-424.

Vautard, R., M. Beekmann, J. Roux, and D. Gombert, 2001: Validation of a hybrid forecasting system for the ozone concentrations over the Paris area. Atmos. Environ., 35,
2449-2461, doi: 10.1016/S1352-2310(00)00466-0. [Link] Vautard, R., D. Martin, M. Beekmann, P. Drobinski, R. Friedrich, A. Jaubertie, D. Kley, M. Lattuati, P. Moral, B. Neininger, and J. Theloke, 2003: Paris emission inventory diagnostics from ESQUIF airborne measurements and a chemistry transport model. J. Geophys. Res., 108, 8564, doi: 10.1029/2002JD002797. [Link]

Venkatram, A., P. Karamchandani, P. Pai, and R. Goldstein, 1994: The development and application of simplified ozone modeling system (SOMS). Atmos. Environ., 28, 3665-3678, doi: 10.1016/1352-2310(94)00190-V. [Link] 